\title{
Phytochrome signal transduction pathways are regulated by reciprocal control mechanisms
}

\author{
Chris Bowler, ${ }^{1,3}$ Hiroshi Yamagata, ${ }^{1,4}$ Gunther Neuhaus, ${ }^{2}$ and Nam-Hai Chua ${ }^{1,5}$ \\ ${ }^{1}$ Laboratory of Plant Molecular Biology, The Rockefeller University, New York, New York 10021-6399 USA; ${ }^{2}$ Institut für \\ Pflanzenwissenschaften, ETH-Zurich, CH-8092 Zürich, Switzerland
}

Three signal transduction pathways, dependent on cGMP and/or calcium, are utilized by phytochrome to control the expression of genes required for chloroplast development and anthocyanin biosynthesis in plant cells. For example, chs is controlled by a cGMP-dependent pathway, cab is controlled by a calcium-dependent pathway, and fnr is regulated by a pathway that requires both cGMP and calcium. Using a soybean photomixotrophic cell culture and microinjection into the cells of a phytochrome-deficient tomato mutant, we have studied the regulatory mechanisms acting within and between these three signaling pathways. We provide evidence that changes in cGMP levels mediate the observed induction and desensitization of chs gene expression in response to light and demonstrate that high cGMP concentrations cause negative regulation of both the calcium- and the calcium/cGMP-dependent pathways. Conversely, high activity of the calcium-dependent pathway can negatively regulate the cGMP-dependent pathway. We have termed these opposing regulatory mechanisms reciprocal control. In all cases, the molecules that are involved appear to be downstream components of the signal transduction pathways, rather than calcium and cGMP themselves. Furthermore, we have found that the calcium/cGMP-dependent pathway has a lower requirement for cGMP than does the cGMP-dependent pathway. The role of these phenomena in the regulation of plant photoresponses is discussed.

[Key Words: aurea; cGMP; desensitization; negative regulation; phytochrome signal transduction; reciprocal control]

Received June 10, 1994; revised version accepted August 1, 1994.

Light is an important environmental stimulus for plants. It controls many aspects of plant morphogenesis and provides the energy for photosynthesis. The initial event of light perception is carried out by at least three families of photoreceptors that detect different wavelengths within the visible spectrum: the phytochromes (which detect red and far red light), the blue light photoreceptors, and the ultraviolet (UV) light photoreceptors. Of these, the best characterized to date are the phytochromes (Quail 1991; Furuya 1993). By genetic and other approaches, attempts are being made to elucidate the signal transduction events downstream of phytochrome that lead to various plant responses (for review, see Deng 1994).

We have been interested in understanding specifically how phytochrome controls gene expression and have developed an experimental system that employs microinjection to deliver signaling intermediates into the cells of a tomato mutant known as aurea, which has greatly re-

Present addresses: ${ }^{3}$ Stazione Zoologica, Villa Comunale 1, 80121 Naples, Italy; ${ }^{4}$ Laboratory of Biochemistry, Faculty of Agriculture, Kobe University, Nada, Kobe 657, Japan.

${ }^{5}$ Corresponding author. duced phytochrome levels (chiefly because of reduced PhyA activity) (Neuhaus et al. 1993; Bowler et al. 1994). Using this system, we have found that PhyA acts through heterotrimeric $\mathrm{G}$ protein activation to stimulate gene expression that results in chloroplast development and anthocyanin biosynthesis (Neuhaus et al. 1993). Downstream of G-protein activation we have identified three different signal transduction pathways that are dependent on cyclic GMP (cGMP) and calcium. The activation of genes encoding anthocyanin biosynthetic enzymes is dependent only on cGMP, whereas calcium and subsequently calcium-activated calmodulin $\left(\mathrm{Ca}^{2+}\right.$ / $\mathrm{CaM}$ / can stimulate the development of immature chloroplasts that lack two of the photosynthetic complexes, photosystem I (PSI) and cytochrome $b_{6} f\left(C y t . b_{6} f\right)$. A third pathway, dependent on both calcium and cGMP, operates to control the synthesis of these two complexes to produce a fully mature (and presumably operational) chloroplast (Neuhaus et al. 1993; Bowler et al. 1994).

It is clearly of interest that these phytochrome signal transduction pathways are divided along functional lines, for example, photosystem II (PSII) synthesis and assembly is dependent on a signaling pathway different 
from that utilized for PSI. The relative inputs into these different transduction pathways may therefore be a means by which plant cells can adjust their biochemical status, particularly for controlling the levels of photoprotectants (such as anthocyanins) and the relative amounts of different photosynthetic complexes. If this were the case, one would predict the existence of cross talk mechanisms between the different phytochrome pathways, which would allow the activities of each pathway to be known by the others and would allow regulatory signals to pass between them. The study presented here was designed to detect such mechanisms by specifically manipulating signal flow through the different pathways. Regarding end products of the signal transduction pathways, we have followed changes in the expression of genes known to be regulated by cGMP, calcium, or both in a photomixotrophic soybean cell culture, SB-P (Horn et al. 1983). In addition, we have performed equivalent experiments using our microinjection approach in aurea cells. Experiments with the SB-P cells have the advantage that they produce quantitative data about gene expression, whereas microinjection in aurea allows analysis in a phytochrome-compromised background and allows the direct manipulation of the components of the signal transduction pathways themselves. As expected, our results suggest the existence of cross-talk mechanisms that control the activities of these signal transduction pathways and ultimately gene expression. In particular, we provide evidence for a novel mechanism of control in which a positive regulator of one signal transduction pathway can negatively regulate another pathway, and vice versa, a phenomenon that we propose to call reciprocal control.

\section{Results}

chs gene expression displays desensitization and adaptation

We and others have shown previously that several genes are induced in soybean SB-P cultures exposed to light and that phytochrome is a mediator of this inducibility (Lam et al. 1989; Romero and Lam 1993; Bowler et al. 1994). To examine further the signaling mechanisms that control this regulation, we chose to study representative genes induced by each of the phytochrome signal transduction pathways characterized previously. As a target of the CGMP pathway we studied chalcone synthase (chs, a gene encoding an anthocyanin biosynthetic enzyme), as a target of the calcium pathway we used $c a b$ (a gene encoding a PSII chlorophyll a,b-binding protein (Ihcb1*1) (Jansson et al. 1992) from the light-harvesting complex (LHCII), and as a target of the calcium/cGMP pathway we studied expression of the gene encoding the PSI component ferredoxin $\mathrm{NADP}^{+}$oxidoreductase $(f n r)$.

As shown in Figure 1a, when 3-day-dark-adapted cultures were exposed to white light for extended periods of time the light induction profiles of the three genes were very different. The $c a b$ gene was induced strongly up to $7 \mathrm{hr}$ and then decreased gradually before rising again after $21 \mathrm{hr}$. Such a pattern of expression is similar to that observed when etiolated seedlings are exposed to light (e.g., Millar et al. 1992), and the second peak is thought to be controlled by the circadian clock. This similarity suggests that $c a b$ gene regulation in the soybean culture may also be under circadian control.

chs and fnr mRNA levels clearly do not cycle, however. In response to light, fnr mRNA abundance increases steadily and then plateaus, whereas chs mRNA increases very rapidly and reaches a maximum after $\sim 3$ hr (Fig. 1a). Subsequently, transcript levels decline sharply and by $7 \mathrm{hr}$ chs mRNA is again at levels found in dark-adapted cultures. Typically, it does not rise again. Such a transient pattern is similar to that observed previously for chs mRNA levels and for chs gene transcription in irradiated parsley cell cultures (Bruns et al. 1986; $\mathrm{Ohl}$ et al. 1989). Furthermore, the synthesis of anthocyanin biosynthetic enzymes and the expression of genes encoding them (such as chs) follow similar transient pat-

a

b
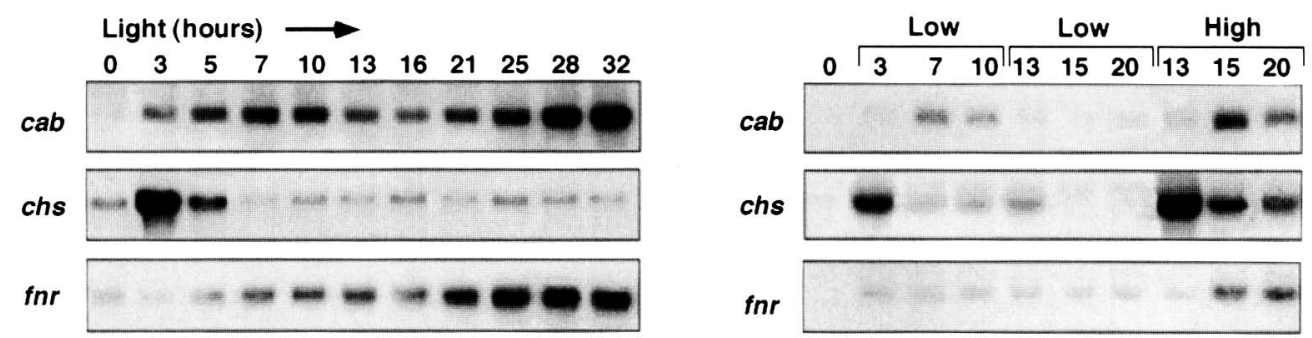

Figure 1. Expression patterns of $c a b, c h s$, and $f n r$ in response to light in SB-P cells, as examined by Northern blot analysis. (a) Gene photoinduction in dark-adapted cultures. Three-day-dark-adapted SB-P cells were exposed to light $(50 \mu \mathrm{moles} / \mathrm{meter}$ per sec) for the times indicated. Note that $c a b$ mRNA levels appear to display a circadian rhythm, whereas chs mRNA is induced rapidly and then returns to dark levels. $(b)$ Adaptation of gene expression to light of different intensities. Dark-adapted cells were exposed initially to low-intensity white light $(2.5 \mu$ moles/meter per sec); (Low) for $10 \mathrm{hr}$ and were then divided into two. For a further $10 \mathrm{hr}$, one was maintained at the low light intensity while the other was shifted to a higher light intensity (50 $\mu \mathrm{moles} / \mathrm{meter} \mathrm{per} \mathrm{sec}) ;$ (High). Times are indicated in hours. 
terns in germinating seedlings of some plant species. This has been interpreted as an adaptive phenomenon for photoprotection in a newly irradiated plant (Mohr and Drumm-Herrel 1983; Brödenfeldt and Mohr 1988; Kubasek et al. 1992).

Additionally, this transient pattern of expression is highly reminiscent of the desensitization phenomena described in animal cells, in which continued exposure to a stimulus results in alterations in the sensitivity and responsiveness to it. In many cases, these alterations are brought about by modulating the flow of information through signal transduction pathways, which can eventually switch themselves off in spite of continued stimulation (e.g., see Koutalos and Yau 1993; Lefkowitz 1993). If the decrease in chs mRNA observed in SB-P cells after $3 \mathrm{hr}$ light irradiation was a result of desensitization, we would predict that when a culture that has been adapted to one light intensity was exposed to a higher intensity there would be another peak of expression followed by subsequent adaptation to the new intensity. This was tested by exposing dark-adapted cultures to low-intensity light for $10 \mathrm{hr}$ and then shifting them to a higher light intensity. chs expression in response to light of low intensity was typical in that mRNA abundance was maximal at $3 \mathrm{hr}$ and then decreased rapidly, but subsequent exposure to the higher light intensity resulted in another peak of expression that decreased normally (Fig. 1b). cab and fnr were induced weakly by low-intensity light and were then induced more strongly by the higher light intensity (Fig. lb).

\section{Modulation of CGMP levels controls chs gene expression}

The phytochrome-stimulated induction of chs and the whole anthocyanin biosynthetic pathway have been shown to be mediated by cGMP (Bowler et al. 1994). Furthermore, we have found that if a membrane-permeable nonhydrolyzable cGMP analog (8-Br-cGMP) is used as the agonist of chs expression instead of light, chs expression is maintained at high levels indefinitely (Bowler et al. 1994). This indicates that light may normally affect chs expression by initially stimulating an increase in cGMP concentrations (leading to chs induction) and then a decrease (leading to chs desensitization). To test this possibility we studied the effects of 8 -Br-cGMP in more detail.

If 8-Br-cGMP $(50 \mu \mathrm{M})$ was added to dark-adapted cultures that were subsequently exposed to light, chs induction was stronger than usual and mRNA levels no longer decreased after $3 \mathrm{hr}$ (Fig. 2a). Furthermore, addition of 8-Br-cGMP at the 3-hr peak of chs expression resulted in the maintenance of high mRNA levels for at least another $8 \mathrm{hr}$ (Fig. 2b). We also found that if 8 -Br-cGMP was added to a light-adapted culture /defined here as a 3-daydark-adapted culture that has been exposed to light for $10 \mathrm{hr}$ or more), in which chs mRNA levels are minimal, it was able to stimulate chs expression again and mRNA levels did not subsequently decrease (Fig. 2c). These data thus reinforce our hypothesis that cGMP is sufficient to stimulate chs expression and show that it is able to do so in both dark- and light-adapted cultures as well as in light-induced cultures. Because 8-Br-cGMP is nonhydrolyzable, the observation that it stimulates chs gene expression that does not attenuate would indicate that reductions in cGMP concentrations mediated by light are responsible for chs desensitization under normal conditions.

Interestingly, the increases in chs expression mediated by 8 -Br-cGMP were reflected by a decrease in the $c a b$ mRNA levels in these cultures (Figs. 2a-c). This was also found to be the case for fnr mRNA (data not shown). This suggested that in addition to being a positive regulator of a
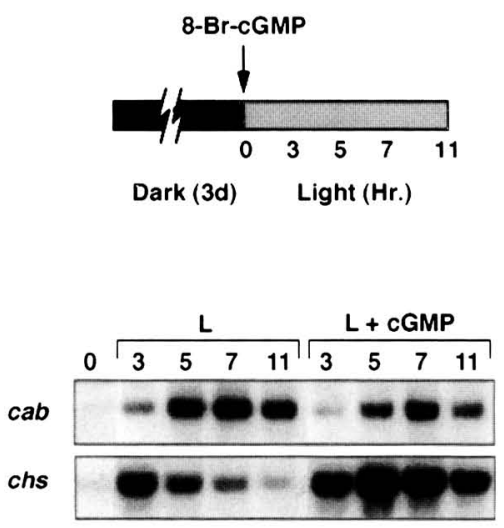

b
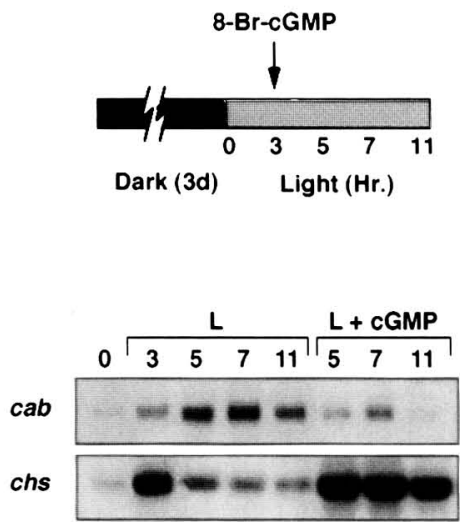

C
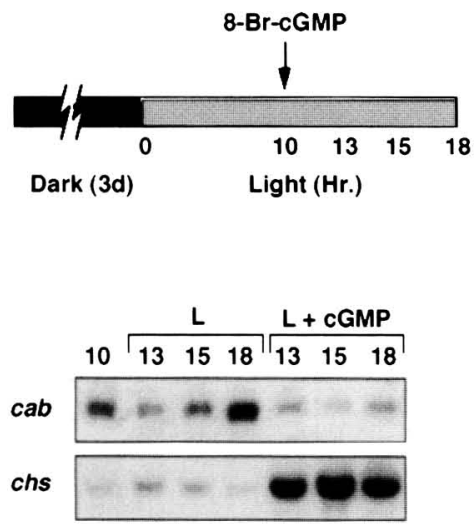

Figure 2. cGMP levels modulate chs gene expression in SB-P cultures. Relief of $c h s$ desensitization by addition of $50 \mu \mathrm{M} 8$-Br-cGMP to dark-adapted cultures immediately prior to their exposure to light $(a)$, to dark-adapted cultures exposed to light for 3 hr $(b)$, and to 10-hr light-adapted cultures $(\mathrm{c})$. Note that in all three cases, the increase in chs mRNA levels is accompanied by a parallel decrease in $c a b$ mRNA. Times are indicated in hours. In each case, the experimental design is schematized above the actual results. 
chs, cGMP may also have a role in down-regulating the calcium pathway.

Although these and our previous data (Bowler et al. 1994) identify cGMP as a likely candidate for controlling the phytochrome-induced expression pattern of chs, they do not indicate whether phytochrome acts by regulating cGMP synthesis [via guanylyl cyclase (GC)], hydrolysis [via cGMP-dependent phosphodiesterase (PDE)], or both. In a first attempt to distinguish between these possibilities we examined the effects of compounds, characterized previously in animal cells, which are able to modulate the activities of these enzymes and result in increased levels of cGMP. Sodium nitroprusside (SNP) generates nitric oxide (NO), which activates GC (Tremblay et al. 1988; Moncada et al. 1991), whereas zaprinast $(\mathrm{M}+\mathrm{B} 22,948)$ is a highly specific inhibitor of PDE (Beavo and Reifsnyder 1990).

In dark-adapted cultures we found that SNP $(100 \mu \mathrm{M})$ could stimulate chs expression in the dark in much the same way as 8 -Br-cGMP; induced levels were similar, and the kinetics of induction and maintenance of expression levels were generally equivalent (Fig. 3a). Zaprinast, however, was not able to promote a response (Fig. 3a). In light-adapted cultures the effects of 8-Br-cGMP and SNP were again highly similar, but in this case zaprinast (100 $\mu \mathrm{M}$ ) could promote an induction (Fig. 3b). The kinetics of zaprinast induction were different to the inductions mediated by 8 -Br-cGMP and SNP, in that $10 \mathrm{hr}$ were typically required for induction, whereas 8-Br-cGMP and SNP could stimulate expression within $3 \mathrm{hr}$ in lightadapted cultures (Fig. 3b). However, levels induced by zaprinast have been found to be maintained for up to 24 hr, like 8-Br-cGMP and SNP (data not shown).

Assuming the specificity of zaprinast, the observation that it was only effective in light-adapted and not in dark-adapted cultures would suggest that PDE (and consequently $\mathrm{GCl}$ is only active in the former, that is, that there is no cGMP current in the dark. However, the observation that zaprinast requires $10 \mathrm{hr}$ to stimulate $c h s$ in a light-adapted culture (in contrast to $3 \mathrm{hr}$ for $8-\mathrm{Br}$ cGMP and SNP) (Fig. 3b) may suggest that the activity of the cyclase becomes greatly decreased in light-adapted cells (compared with light-induced cells) and that a long period of time is required to build up cGMP to signal- transducing levels. Assuming that SNP acts by modulating GC activity, the observation that it can stimulate chs gene expression in both light- and dark-adapted cultures would suggest that the cyclase is present in both, that is, that it does not have to be synthesized de novo in the light, but light somehow stimulates and then modulates its activity. Whether NO is the physiological activator of plant GC obviously remains to be determined.

As noted previously (Fig. 2a,b), the increases in chs expression mediated by these compounds were accompanied by decreases in $c a b$ mRNA levels (Fig. 3). fnr mRNA followed similar patterns (data not shown). This was particularly apparent in light-adapted cultures (Fig. $3 \mathrm{~b}$ ), because $c a b$ mRNA at the beginning of the experiment was much more abundant than it was in darkadapted cultures. In this case, the effects of these compounds on $c a b$ mRNA reflect either a higher decay rate or an increased efficiency of dark repression of the $c a b$ gene or both (because the incubations with the inhibitors were done in the darkl. Note that the kinetics of the reciprocal effects on chs and $c a b$ are parallel, for example, the reduction in $c a b$ mRNA was only apparent after $10 \mathrm{hr}$ in the presence of zaprinast, whereas it was already clear after $3 \mathrm{hr}$ when 8-Br-cGMP or SNP were used (Fig. 3b).

\section{Induction of chs is sensitive to genistein}

In addition to modulating cGMP concentrations we also attempted to use compounds with known pharmacological effects in animal cells to identify inhibitors that would specifically affect the cGMP pathway and not the calcium pathway. One such inhibitor that we found to be highly specific in its effect was genistein, characterized as being an inhibitor of tyrosine and histidine $\mathrm{ki}$ nases in animal cells (Akiyama et al. 1987; Huang et al. 1992). Figure $4 \mathrm{a}$ shows that the light induction of chs was completely inhibited in the presence of genistein 175 $\mu \mathrm{M})$, whereas $c a b$ and fnr photoinduction were unaffected. These results would thus identify the genisteinsensitive step as being far downstream in the cGMP pathway (see Fig. 8a, below), because it does not affect fnr photoinducibility.

It was also of interest to determine whether genistein a

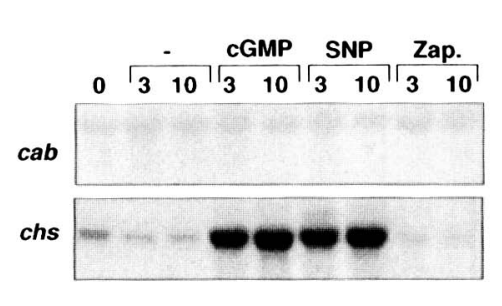

b

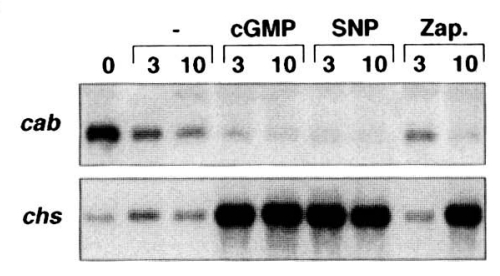

Figure 3. Comparison of the ability of 8-Br-cGMP, SNP, and zaprinast to stimulate chs gene expression in dark- and lightadapted SB-P cultures. In $a$, either $8-\mathrm{Br}$ cGMP $(50 \mu \mathrm{M})$ (cGMP), SNP (100 $\mu \mathrm{M})$ (SNP), or zaprinast $(100 \mu \mathrm{M})$ (Zap.) was added to dark-adapted cultures and samples were taken after a further $3 \mathrm{hr}$ or $10 \mathrm{hr}$ in darkness. In $b$, the experiment was identical except that light-adapted cells were used as starting material. As seen previously, in light-adaped cultures the increases in chs mRNA are reflected by decreases in $c a b$ mRNA. 
Figure 4. Control of chs gene expression in $\mathrm{SB}-\mathrm{P}$ cells by a genistein-sensitive component. $(a)$ chs photoinduction is inhibited by genistein, whereas $c a b$ and $f n r$ expression are unaffected. Genistein (75 $\mu \mathrm{M})$ (Gen.) was added to dark-adapted cultures $30 \mathrm{~min}$ prior to their exposure to light. Times are indicated in hours. $(b)$ The 8-Br-cGMP-, SNP-, and zaprinast-mediated inductions of chs are also sensitive to genistein. Genistein $(75 \mu \mathrm{M})$ (Gen.) was added to light-adapted cultures together with DMSO $(-1,50 \mu \mathrm{M} 8$-Br-cGMP (cGMP), $100 \mu \mathrm{M}$ SNP (SNP), or $100 \mu \mathrm{M}$ zaprinast (Zap.). The - and + denote the absence or presence of genistein, respectively. Following the appropriate additions, cultures $(30 \mathrm{ml})$ were placed in the dark and samples were taken for RNA isolation after $10 \mathrm{hr}$. The inhibition of chs induction by genistein is accompanied by an inhibition of the increase in the dark decay rate of cab mRNA mediated by the various agonists, indicating that the negative regulation of the calcium pathway by the cGMP pathway also requires the genistein-sensitive component.

could inhibit the 8-Br-cGMP-, SNP-, and zaprinast-mediated inductions of chs. Figure $4 \mathrm{~b}$ details results of experiments using light-adapted cultures. Clearly, genistein was able to inhibit chs inductions mediated by all three of these compounds. Furthermore, we found that it could inhibit the inductions of chs mediated by 8-Br-cGMP and SNP in dark-adapted cultures (data not shown). These results indicate that the genistein-sensitive component is essential for the chs induction mediated by all of these compounds, as it is for the lightmediated induction, suggesting that the same signal transduction pathway is being activated in each case. Furthermore, the fact that it inhibits chs induction by 8-Br-cGMP indicates that the genistein-sensitive component is downstream of cGMP (see Fig. 8a).

Again, as noted previously, $c a b$ mRNA levels were decreased in the presence of these compounds. Interestingly, however, this decrease was inhibited by genistein (Fig. 4b), indicating that the genistein-sensitive component of the cGMP pathway (or something downstream of it) is also necessary for the observed down-regulation of the calcium pathway. If this is the case, it would mean that cGMP per se was not able to modulate the calcium pathway directly, but that it acts through a downstream target which is sensitive to genistein. Again, as noted previously, changes in fnr mRNA abundance were highly similar to those shown for $c a b$ mRNA (data not shown).

To test the specificity of genistein in an independent system, we utilized the aurea mutant of tomato in microinjection experiments similar to those reported previously (Neuhaus et al. 1993; Bowler et al. 1994). Using $\beta$-glucuronidase (Gus)-based cab-gus, chs-gus, and fnrgus as reporters for phytochrome responses we determined whether genistein was able to inhibit the normal induction of these reporter genes in aurea hypocotyl cells when they were coinjected with PhyA. Table 1 shows that the PhyA-stimulated induction of chs-gus, but neither cab-gus nor fnr-gus, was inhibited in the presence of genistein, consistent with our RNA data from SB-P cells. Furthermore, the activation of chs-gus by the $G$ protein activators GTP $\gamma S$ and cholera toxin
(CTX) was also inhibited by genistein, whereas cab-gus and $f n r$-gus were unaffected (Table 1). To confirm that the genistein-sensitive component was distal of cGMP we incubated cGMP-injected material with genistein. As predicted from the SB-P data, the CGMP-mediated induction of chs-gus was inhibited by genistein (Table 1). These results are thus consistent with those obtained from the soybean cells, suggesting that the importance of the genistein-sensitive component for the cGMP-mediated phytochrome signal transduction pathway has been well conserved in plants.

The importance of the genistein-sensitive component for phytochrome signaling is also underlined by the fact that it was able to block the phytochrome-mediated stimulation of the whole anthocyanin biosynthetic pathway in aurea (Fig. 5). However, as predicted from the soybean experiments, genistein had no effect on PhyAstimulated chloroplast development: Immunofluorescence analysis demonstrated that all of the major photosynthetic complexes [PSI, PSII, Cyt. $b_{6} f$, ATP synthase, and ribulose 1,5-bisphosphate carboxylase (RUBISCO)] were present in the plastids of cells injected with PhyA and subsequently incubated in genistein (Fig. 5). We also found that GTPyS-injected cells responded in the same way to genistein (data not shown). Taken collectively, these data confirm that the genistein-sensitive component is downstream of the bifurcation between the cGMP- and the calcium/cGMP-dependent pathways /see Fig. 8a, below).

\section{Identification of inhibitors that block calcium- dependent gene expression}

The results presented above suggest that a downstream component of the cGMP pathway is able to negatively regulate the calcium pathway. It seemed possible, therefore, that one (or several) component(s) of the calcium pathway may be able to regulate the cGMP pathway in a similar fashion. To examine this, it was of interest to identify specific inhibitors that were able to block calcium- but not cGMP-dependent gene expression. Obvi- 
Table 1. Summary of microinjection experiments using gus reporter genes in aurea

\begin{tabular}{|c|c|c|c|c|}
\hline \multirow[b]{2}{*}{ Injected material } & \multirow[b]{2}{*}{ Inhibitor } & \multicolumn{3}{|c|}{ Efficiency $(\%)$ (no activations/no injections) } \\
\hline & & $c a b$-gus & chs-gus & fnr-gus \\
\hline PhyA & - & $10.3(13 / 126)$ & $10.6(15 / 142)$ & $8.0(13 / 163)$ \\
\hline Injection buffer & - & $-(0 / 112)$ & $-(0 / 120)$ & $-(0 / 131)$ \\
\hline PhyA & genistein & $8.1(12 / 148)$ & $-(0 / 160)$ & $7.0(9 / 128)$ \\
\hline PhyA & trifluoperazine & $-\mid 0 / 290\}$ & $10.7(16 / 150)$ & $-(0 / 128)$ \\
\hline PhyA & nifedipine & $-\{0 / 312\}$ & $8.5(18 / 212)$ & $-\{0 / 121\}$ \\
\hline PhyA & staurosporine & $-(0 / 130)$ & $12.3(16 / 130)$ & $-(0 / 160)$ \\
\hline $\mathrm{GTP} \gamma \mathrm{S}$ & - & $10.9(12 / 110)$ & $8.0(8 / 100)$ & $9.0(9 / 100)$ \\
\hline GTP $\gamma \mathrm{S}$ & genistein & $11.9(19 / 160)$ & $-(0 / 140)$ & $10.7(16 / 150)$ \\
\hline GTP $\gamma \mathrm{S}$ & trifluoperazine & $-(0 / 130)$ & $12.8(16 / 125)$ & $-(0 / 122)$ \\
\hline GTP $\gamma \mathrm{S}$ & nifedipine & $-(0 / 125)$ & $8.1(10 / 123)$ & $-(0 / 115)$ \\
\hline GTP $\gamma \mathrm{S}$ & staurosporine & $-|0 / 132|$ & $12.0(17 / 142)$ & N.D. \\
\hline CTX + GTPyS & - & $9.2(11 / 120)$ & $11.1(10 / 90)$ & $6.7(8 / 120)$ \\
\hline CTX + GTPyS & genistein & $10.4(12 / 115)$ & $-\langle 0 / 132\}$ & $6.2(8 / 130)$ \\
\hline CTX + GTP $\gamma S$ & nifedipine & $-(0 / 122)$ & $10.9(12 / 110)$ & $-(0 / 130)$ \\
\hline $\mathrm{Ca}^{2+}$ & - & $13.3(12 / 90)$ & $-(0 / 100)$ & $-(0 / 125)$ \\
\hline $\mathrm{Ca}^{2+}$ & trifluoperazine & $-(0 / 142)$ & $-|0 / 110|$ & $-|0 / 123|$ \\
\hline $\mathrm{Ca}^{2+}$ & nifedipine & $11.7(14 / 120)$ & $-(0 / 121)$ & $-(0 / 132)$ \\
\hline $\mathrm{Ca}^{2+}$ & staurosporine & $-|0 / 62|$ & $-|0 / 85|$ & $-(0 / 72)$ \\
\hline $\mathrm{Ca}^{2+} / \mathrm{CaM}$ & - & $11.4(10 / 88)$ & $-(0 / 100)$ & $-(0 / 100)$ \\
\hline $\mathrm{Ca}^{2+} / \mathrm{CaM}$ & trifluoperazine & $-(0 / 81)$ & $-(0 / 71)$ & $-(0 / 55)$ \\
\hline $\mathrm{Ca}^{2+} / \mathrm{CaM}$ & nifedipine & $11.5(14 / 122)$ & $-|0 / 142|$ & $-(0 / 110)$ \\
\hline $\mathrm{Ca}^{2+} / \mathrm{CaM}$ & staurosporine & $-(0 / 78)$ & $-|0 / 105|$ & N.D. \\
\hline cGMP & - & $-(0 / 121)$ & $6.9(9 / 130)$ & $-(0 / 120)$ \\
\hline cGMP & genistein & $-(0 / 120)$ & $-|0 / 128|$ & $-(0 / 125)$ \\
\hline cGMP & nifedipine & $-(0 / 138)$ & $11.6(14 / 121)$ & $-(0 / 117)$ \\
\hline
\end{tabular}

Efficiency of Gus activation (expressed in \%) following different treatments is shown, together with actual experimental data in parentheses (showing the total number of injections and the number of activations). Concentrations of injected materials (expressed as estimated final intracellular concentrations (Neuhaus et al. 1993) are as follows: (PhyA) 10,000 molecules; (GTP $\gamma$ S) $50 \mu \mathrm{M}$ (or $1 \mu \mathrm{M}$ when used with CTX); (CTX) $>1,000$ molecules; $\left(\mathrm{Ca}^{2+}\right) 1 \mu \mathrm{M} ;\left(\mathrm{Ca}^{2+} / \mathrm{CaM}\right) 10,000$ molecules; (cGMP) 30-80 $\mu \mathrm{M}$. CaM was activated by $\mathrm{Ca}^{2+}$ as described previously (Neuhaus et al. 1993). Inhibitors were used as described in Materials and methods. Results for control injections (i.e., without inhibitors) are from new experiments and are in addition to those published previously in Neuhaus et al. (1993) and Bowler et al. (1994). (N.D.) Not done.

ous compounds to test first were those that have been found to affect calcium-dependent processes in animal cells.

Figure 6a shows the effects of trifluoperazine $\left(\mathrm{a} \mathrm{Ca}^{2+} /\right.$ CaM antagonist) (Massom et al. 1990) on light-induced gene expression. This compound has been shown previously to inhibit $c a b$ photoinduction in SB-P cultures (Lam et al. 1989). At concentrations of $25 \mu \mathrm{M}$, we confirmed that trifluoperazine was able to effectively inhibit the photoinduction of $c a b$ and that it could also inhibit the photoinduction of fnr, a result we would expect from a compound that inhibits $\mathrm{Ca}^{2+} / \mathrm{CaM}$ action (see Fig. 8). Interestingly, not only was chs photoinduction not inhibited but it was strongly superinduced (Fig. 6a), suggesting that inhibition of the calcium pathway somehow leads to stimulation of the cGMP pathway.

Similar results were observed with nifedipine, which blocks animal and plant L-type calcium channels (Schroeder and Thuleau 1991; Schumaker and Gizinski 1993). At a concentration of $60 \mu \mathrm{M}$ it could totally inhibit the light induction of $c a b$ and $f n r$, whereas chs induction was again superinduced (Fig. 6b). Another compound, staurosporine, which is a nonspecific inhibitior of animal protein kinases (Rüegg and Burgess 1989), was found to give similar results when added to the cultures at a concentration of $50 \mathrm{~nm}$ (Fig. 6c). Staurosporine has been used previously with suspension-cultured tomato cells, where it was found to inhibit a variety of elicitor-stimulated responses, including phosphorylation of several proteins (Felix et al. 1991).

In all three cases, then, the inhibitor-sensitive step would appear to be downstream of G-protein activation but upstream of the branchpoint between the calcium and the calcium/cGMP pathways (see Fig. 8a). To confirm these locations we performed equivalent experiments with these inhibitors in the microinjection experimental system using aurea. All three compounds were able to block the PhyA- and GTP $\gamma$ S-stimulated expression of cab-gus and fnr-gus, but not chs-gus (Table 1), corroborating the RNA data from SB-P cells. In addition, 


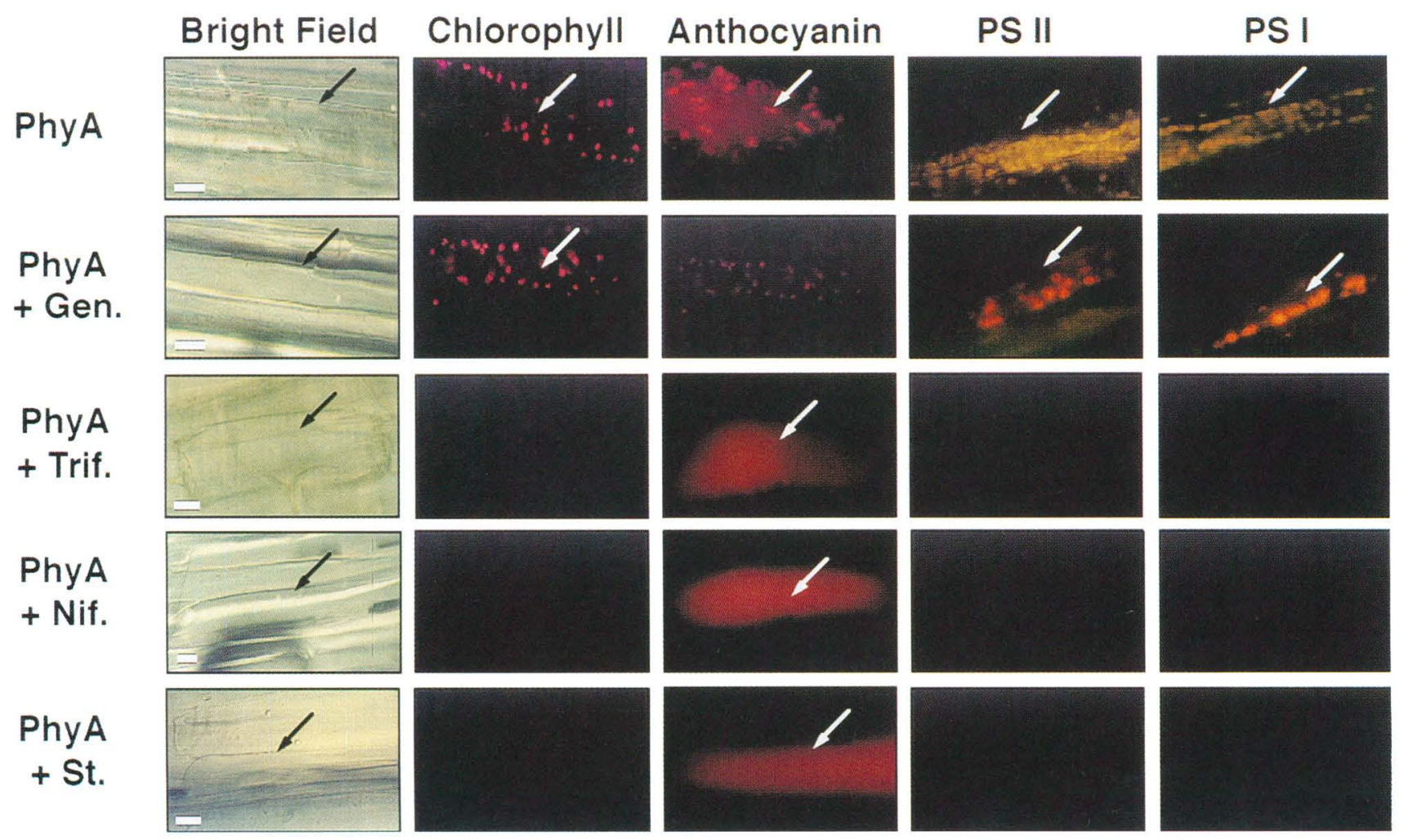

Figure 5. Physiological responses of PhyA-injected aurea hypocotyl cells following incubation with genistein, trifluoperazine, nifedipine, and staurosporine. Cells injected with PhyA $\quad \sim 50,000$ molecules $/$ were analyzed microscopically under bright-field illumination (Bright Field) and under appropriate fluorescent light conditions for detection of chlorophyll autofluorescence within the chloroplasts (Chlorophyll), anthocyanin autofluorescence within the vacuoles, (Anthocyanin) and for FITC immunofluorescence (PS II and PS I) (Neuhaus et al. 1993; Bowler et al. 1994). PhyA-injected cells were either untreated (PhyA), infiltrated with $100 \mu \mathrm{M}$ genistein (PhyA + Gen.), $200 \mu \mathrm{M}$ trifluoperazine (PhyA + Trif.), $125 \mu \mathrm{M}$ nifedipine (PhyA + Nif.), or 60 nM staurosporine (PhyA + St.) prior to incubation for $48 \mathrm{hr}$ in white light. In all micrographs arrows indicate the injected cells. All micrographs are longitudinal sections and the bars on the bright-field micrographs indicate $10 \mu \mathrm{m}$. The fluorescence micrographs are at approximately the same scale as the corresponding bright-field view. For immunofluorescence analysis, specific antibodies against proteins of PSII and PSI were used for analysis. The examples given are with antibodies against LHCII for PSII and ferredoxin for PSI. In all immunofluorescence micrographs a narrow band filter was used to reduce the red fluorescence from chlorophyll (Zeiss special filter; narrow band green). Immunofluorescence using other anti-PSII and anti-PSI antibodies (OEE1, D1, D2, and plastocyanin, PsaD, PsaF, respectively), together with antibodies against Cyt. $b_{6} f$ complex polyeptides (Cyt. $b_{6}$, Cyt.f), ATP synthase (Atp $\alpha$, Atp $\gamma$ ), and RUBISCO (RbcS) all gave identical results to those shown (data not shown).

whereas trifluoperazine and staurosporine inhibited both calcium- and $\mathrm{Ca}^{2+} / \mathrm{CaM}$-stimulated expression of $\mathrm{cab}-$ gus, nifedipine could not block cab-gus expression stimulated by either of them (Table 1). This would indicate that the nifedipine-sensitive component lies between the $G$ protein and calcium and that the trifluoperazineand staurosporine-sensitive components are at or downstream of $\mathrm{Ca}^{2+} / \mathrm{CaM}$ but upstream of the bifurcation between the two calcium-dependent pathways /see Fig. 8 a).

We also observed that the development of chloroplasts induced by injection of PhyA or GTP $\gamma$ S was completely inhibited in the presence of trifluoperazine, nifedipine, or staurosporine but that these compounds had no effect on the stimulation of anthocyanin pigment production by PhyA or GTP $\gamma \mathrm{S}$. Examples of this are shown in Figure 5, with PhyA-injected cells that were subsequently incubated in trifluoperazine, nifedipine and staurosporine.
Negative regulation of the cGMP pathway by the calcium pathway

Figure $6 a, b$, and $c$, shows that, in addition to inhibiting calcium-dependent gene expression, trifluoperazine, nifedipine, and staurosporine are able to superinduce chs gene expression in response to light. To examine this phenomenon further, we chose to study the effects of these compounds in more detail. The results of experiments using trifluoperazine are shown in Figures $6 \mathrm{~d}$ and 7.

Trifluoperazine $(25 \mu \mathrm{M})$ is able to augment the level of chs expression at the normal $3 \mathrm{hr}$ peak, whereas $c a b$ gene expression in response to light remains fully inhibited (Fig. 6d). In addition to blocking calcium-dependent responses, this compound therefore appears to increase chs expression (but does not appear to affect desensitization, because chs mRNA decreases after $3 \mathrm{hr}$ ). Its effects on 
a

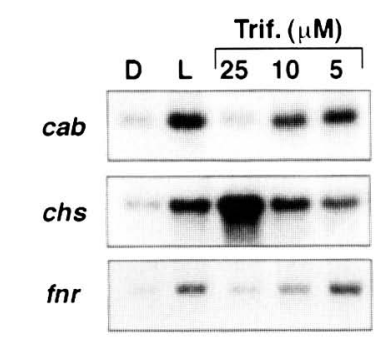

b

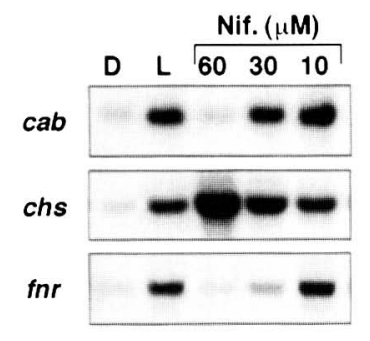

C

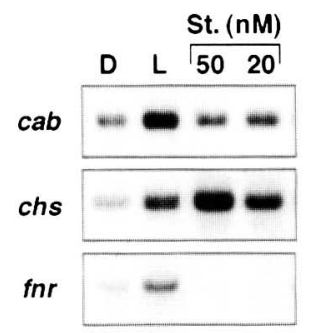

d

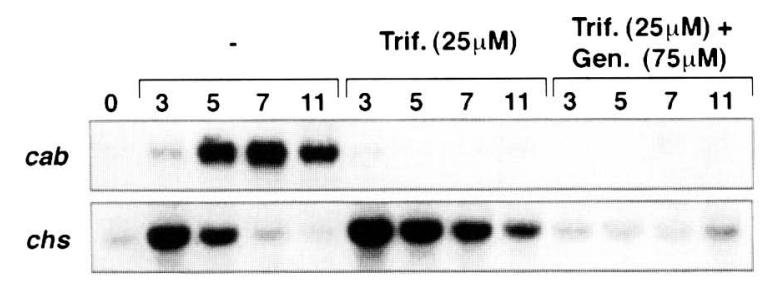

Figure 6. Identification of inhibitors that block calcium-dependent responses in SB-P cells. Inhibition of $c a b$ and fnr photoinduction by $25 \mu \mathrm{M}$ trifluoperazine (Trif.) ( $a$ ), by $60 \mu \mathrm{M}$ nifedipine (Nif.) / b), and by $20 \mathrm{~nm}$ and $50 \mathrm{~nm}$ staurosporine (St.) (c). Samples were taken for RNA analysis after $5 \mathrm{hr}$ exposure to light, a time at which the mRNAs of all three of the genes studied were present. In all cases, the inhibition of $c a b$ and $f n r$ is accompanied by an increase in chs mRNA levels. (d) The trifluoperazine-mediated superinduction of chs is sensitive to genistein. Thirty minutes prior to exposure to light, dark-adapted cells were either untreated $(-)$, treated with 25 $\mu \mathrm{M}$ trifluoperazine (Trif.), or with both $25 \mu \mathrm{M}$ trifluoperazine and $75 \mu \mathrm{M}$ genistein (Trif. + Gen.). Times are indicated in hours.

chs (but not $c a b$ or fnr) gene expression are inhibited by genistein (Fig. 6d), showing again that the genistein-sensitive component of the cGMP pathway is critical for chs gene induction. The superinductions of $c h s$ mediated by nifedipine and staurosporine were similar to that of trifluoperazine and were also sensitive to genistein (data not shown).

We were then interested to learn whether trifluoperazine could affect the 8-Br-cGMP-mediated induction of chs. This was examined in both light- and dark-adapted cultures. In neither culture was the addition of trifluoperazine alone able to induce chs gene expression, in clear contrast to the effects of 8-Br-cGMP (Figs. 7a,b). Furthermore, again unlike 8-Br-cGMP, in light-adapted cultures placed in the dark, it did not increase the decay rate of $c a b$ mRNA either (Fig. 7a), indicating that its effects on steady-state $c a b$ mRNA levels in the light are probably not a result of mRNA destabilization but more likely reflect an interaction that affects gene expression. Interestingly, the addition of 8-Br-cGMP, together with trifluoperazine to light-adapted cultures, led to a superinduction of chs and an increased decay rate of $c a b$ mRNA (Fig. 7a), but in dark-adapted cultures trifluoperazine affected neither the 8-Br-cGMP-mediated induction of chs nor the 8-Br-cGMP-mediated decrease in $c a b$ mRNA levels (Fig. $7 \mathrm{~b}$ ). This suggests that the trifluoperazine-sensitive component of the phytochrome-activated calcium pathway (perhaps $\mathrm{Ca}^{2+} / \mathrm{CaM}$ ), or something down- a

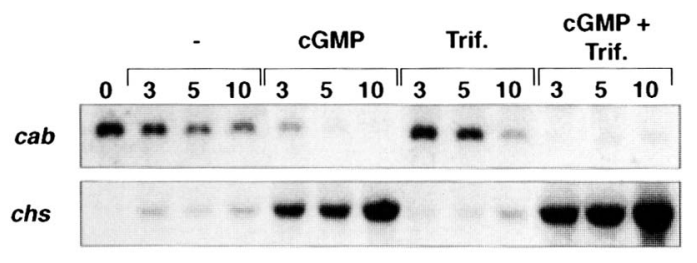

b

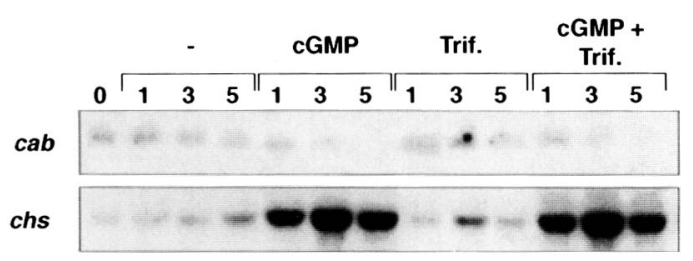

Figure 7. Superinduction of the 8-Br-cGMP-mediated stimulation of chs expression by trifluoperazine in SB-P cells. Cultures were either untreated $(-)$, treated with $50 \mu \mathrm{M}$ 8-Br-cGMP (cGMP), $25 \mu \mathrm{M}$ trifluoperazine (Trif.), or with both 8-Br-cGMP and trifluoperazine (cGMP + Trif.) for the times indicated (in hours). (a) Effect of these additions to a light-adapted culture; $(b)$ effect of these compounds in a dark-adapted culture. Trifluoperazine is only able to superinduce the 8-Br-cGMP-mediated induction of chs in light-adapted cultures. In all cases, the abundance of chs mRNA is reflected as a mirror image in the abundance of $c a b$ mRNA. 
stream of it, in addition to being a positive regulator of the calcium pathway, is also a negative regulator of chs expression. Nifedipine and staurosporine have equivalent effects to trifluoperazine in light- and dark-adapted cultures (data not shown), indicating that the effector must be either the most downstream target for these three compounds or even farther downstream in the calcium pathway. fnr mRNA levels showed variations much like those shown for $c a b$ (data not shown).

Utilization of aurea in microinjection experiments allowed the study of these control mechanisms by directly manipulating the levels of the signaling molecules themselves, rather than working indirectly with inhibitors that block their action. For these experiments we wanted to keep the level of one signaling molecule constant but to vary the concentration of another from a different pathway. Initially, we chose to work with constant cGMP (75 $\mu \mathrm{M}$; estimated final intracellular concentration) and vary the levels of $\mathrm{Ca}^{2+} / \mathrm{CaM}$, because $\mathrm{Ca}^{2+}$ $\mathrm{CaM}$ could be used over a wide concentration range: Whereas 5000 molecules of $\mathrm{Ca}^{2+} / \mathrm{CaM}$ are sufficient to stimulate cab-gus expression (Neuhaus et al. 1993), we have found that injection of as much as 100,000 molecules can be used without detriment to the cells (data not shown).

As shown previously (Table 1; Neuhaus et al. 1993; Bowler et al. 1994), injection of cGMP $(\sim 75 \mu \mathrm{M})$ could stimulate only chs-gus, whereas injection of $\sim 10,000$ molecules of $\mathrm{Ca}^{2+} / \mathrm{CaM}$ could stimulate only cab-gus (Table 2). Also consistent with previous observations (Bowler et al. 1994), when these amounts were coinjected we found that all three reporter genes were activated (Table 2). This was also true when 5000 molecules of $\mathrm{Ca}^{2+} / \mathrm{CaM}$ were coinjected with cGMP, although 2000 molecules were not sufficient to provoke any response above the normal cGMP response (Table 2). Interestingly, coinjection of higher amounts of $\mathrm{Ca}^{2+} / \mathrm{CaM}$ $(100,000$ molecules and also 50,000 molecules, to some extent/ with cGMP had the effect of inhibiting chs-gus, in spite of continued expression of cab-gus (Table 2). This result is therefore a direct demonstration that $\mathrm{Ca}^{2+} / \mathrm{CaM}$ (or something downstream of it), in addition to positively regulating the calcium pathway, is also able to negatively regulate the cGMP pathway. Calmodulin not activated with calcium (CaM) had no stimulatory or inhibitory effects in these experiments (Table 2), demonstrating clearly the specificity of the responses for the active form of calmodulin $\left(\mathrm{Ca}^{2+} / \mathrm{CaM}\right)$. The results also reveal that there is no negative regulation by $\mathrm{Ca}^{2+} / \mathrm{CaM}$ (or the downstream component) acting on the third calcium/cGMP pathway, because fnr-gus was still expressed in the presence of high levels of $\mathrm{Ca}^{2+} / \mathrm{CaM} / \mathrm{Ta}$ ble 2). Furthermore, immunofluorescence analysis of cells coinjected with cGMP and high levels of $\mathrm{Ca}^{2+} /$ $\mathrm{CaM}$ revealed that all of the major photosynthetic complexes were present in the plastids, although anthocyanin fluorescence was not observed (data not shown).

\section{Negative regulation of the calcium pathway by the CGMP pathway}

We then attempted to demonstrate negative regulation acting in the opposite direction, that is, to see whether high cGMP levels could inhibit signal transduction through the calcium pathway. cGMP was only able to stimulate chs-gus within a narrow concentration range

Table 2. Summary of microinjection experiments in aurea demonstrating interactions between phytochrome signal transduction pathways

\begin{tabular}{|c|c|c|c|c|}
\hline \multirow{2}{*}{$\begin{array}{l}\text { cGMP } \\
(\mu \mathrm{M})\end{array}$} & \multirow{2}{*}{$\begin{array}{c}\text { Calmodulin } \\
\text { (no. molecules) }\end{array}$} & \multicolumn{3}{|c|}{ Efficiency $(\%)$ (no. of activations/no. injections) } \\
\hline & & cab-gus & chs-gus & fnr-gus \\
\hline- & $\mathrm{Ca}^{2+} / \mathrm{CaM}(10,000)$ & $11.4(10 / 88)$ & $-(0 / 100)$ & $-(0 / 100)$ \\
\hline- & $\mathrm{CaM}(10,000)$ & $-(0 / 132)$ & $-(0 / 124)$ & $-(0 / 95)$ \\
\hline 75 & $\mathrm{Ca}^{2+} / \mathrm{CaM}(2,000)$ & $-(0 / 125)$ & $10.9(13 / 119)$ & $-(0 / 105)$ \\
\hline 75 & $\operatorname{CaM}(2,000)$ & $-(0 / 75)$ & $16.9(11 / 65)$ & $-(0 / 68)$ \\
\hline 75 & $\mathrm{Ca}^{2+} / \mathrm{CaM}(5,000)$ & $11.8(10 / 85)$ & $10.6(9 / 85)$ & $8.6(7 / 81)$ \\
\hline 75 & $\mathrm{Ca}^{2+} / \mathrm{CaM}(10,000)$ & $9.1(10 / 110)$ & $9.3(12 / 129)$ & $8.6(9 / 105)$ \\
\hline 75 & $\mathrm{Ca}^{2+} / \mathrm{CaM}(50,000)$ & $14.1(12 / 85)$ & $4.2(4 / 95)$ & $10.1(8 / 79)$ \\
\hline 75 & $\mathrm{Ca}^{2+} / \mathrm{CaM}(100,000)$ & $11.1(15 / 135)$ & $-(0 / 145)$ & $7.9(9 / 114)$ \\
\hline 75 & $\mathrm{CaM}(100,000)$ & $-(0 / 79)$ & $12.0(9 / 75)$ & $-|0 / 65|$ \\
\hline- & $\mathrm{Ca}^{2+} / \mathrm{CaM}(3,000)$ & $10.7(13 / 122)$ & $-(0 / 104)$ & $-(0 / 113)$ \\
\hline 75 & $\mathrm{Ca}^{2+} / \mathrm{CaM}(3,000)$ & $12.8(12 / 94)$ & $12.6(13 / 103)$ & $9.2(10 / 109)$ \\
\hline 110 & $\mathrm{Ca}^{2+} / \mathrm{CaM}(3,000)$ & $1.6(3 / 187)$ & $16.5(22 / 133)$ & $0.6(1 / 154)$ \\
\hline 130 & $\mathrm{Ca}^{2+} / \mathrm{CaM}(3,000)$ & * & * & * \\
\hline 5 & - & $-(0 / 95)$ & $-\{0 / 73\}$ & $-(0 / 81)$ \\
\hline 5 & $\mathrm{Ca}^{2+} / \mathrm{CaM}(10,000)$ & $11.0(12 / 109)$ & $-\{0 / 110\}$ & $8.5(9 / 105)$ \\
\hline
\end{tabular}

Efficiency of Gus activation (expressed in \%) following different treatments is shown, together with actual experimental data in parentheses (showing the total number of injections and the number of activations). Concentrations of injected materials are expressed as estimated final intracellular concentrations (Neuhaus et al. 1993). CaM was activated by $\mathrm{Ca}^{2+}$ as described previously (Neuhaus et al. 1993). (*) Injection of $130 \mu \mathrm{M}$ cGMP was toxic to the cells, as evidenced after $24 \mathrm{hr}$ by increased granulation within the cell and by the absence of cytoplasmic streaming. 
(30-110 $\mu \mathrm{M})$, above which it was toxic (Bowler et al. 1994). We therefore coinjected different amounts of cGMP with the lowest amounts of $\mathrm{Ca}^{2+} / \mathrm{CaM}$, which we have found to stimulate cab-gus expression $1 \sim 3000$ molecules). The results of this series of experiments are shown in Table 2. Injection of $\sim 3000$ molecules of $\mathrm{Ca}^{2+} / \mathrm{CaM}$ was sufficient to stimulate $c a b-g u s$ expression, and when this was coinjected with $75 \mu \mathrm{M}$ cGMP (estimated final intracellular concentration) all three reporter genes were activated, as expected. However, when it was coinjected with $110 \mu \mathrm{M}$ cGMP, although the cells remained viable, cab-gus expression was now inhibited whereas chs-gus expression was activated normally. Coinjection of $\mathrm{Ca}^{2+} / \mathrm{CaM}$ with $130 \mu \mathrm{M}$ cGMP was toxic. These results therefore provide a direct demonstration for negative regulation of the calcium pathway by the cGMP pathway, corroborating our data on gene expression from the SB-P cells. Furthermore, these results indicate that high levels of cGMP are also able to inhibit activity of the calcium/cGMP pathway, because fnr-gus expression was inhibited, like cab-gus (Table 2). Cells injected with 3000 molecules of $\mathrm{Ca}^{2+} / \mathrm{CaM}$ and $110 \mu \mathrm{M}$ cGMP were found to lack all of the major photosynthetic complexes, although anthocyanin fluorescence was still observed (data not shown). These results are fully consistent with data from the SB-P cells, which indicated that the decrease in $c a b$ mRNA levels in the presence of 8-Br-cGMP (e.g., Fig. 2) was also observed with fnr mRNA (data not shown). These independent experiments also indicated that it is not cGMP itself that mediates negative regulation but, rather, a component at or downstream of the genistein-sensitive step (Fig. 4).

\section{cGMP requirements of the calcium/cGMP pathway}

The observation that high levels of cGMP could inhibit fnr-gus but not chs-gus expression led us to speculate whether fnr-gus expression may have different concentration requirements for cGMP than does chs-gus. To this end, we coinjected $\mathrm{Ca}^{2+} / \mathrm{CaM}$ with low amounts of cGMP. The data from these experiments are shown in Table 2. Although $5 \mu \mathrm{M}$ cGMP (estimated final concentration/ could not stimulate chs-gus under any conditions, when it was combined with $\mathrm{Ca}^{2+} / \mathrm{CaM}$ it was clearly able to activate fnr-gus, demonstrating that its expression required less cGMP than did chs-gus. We reported previously that chs-gus requires at least $30 \mu \mathrm{M}$ cGMP for activation (Bowler et al. 1994), so these results demonstrate that fnr-gus is able to be activated by concentrations at least sixfold lower. These low levels of cGMP combined with $\mathrm{Ca}^{2+} / \mathrm{CaM}$ could stimulate the production of fully mature chloroplasts (by immunological criteria) but not anthocyanin pigments (data not shown).

\section{Discussion}

cGMP as a regulator of chs gene expression

Our photobiological observations using dark-adapted SB-P cells have shown that chs mRNA levels increase up to a 3-hr peak and then decline rapidly (Fig. 1a), most likely because of desensitization of chs photoinduction as a result of decreasing cGMP levels. This is supported by data from Figure 2, which shows that the exogenous addition of a membrane-permeable cGMP analog, 8-BrcGMP, can both prevent the chs desensitization normally observed after $3 \mathrm{hr}$ in continuous light (Fig. 2a,b) and can release chs from desensitization when added to a light-adapted culture (Fig. 2c). In each case, the fact that the expression stimulated by 8 -Br-cGMP was not subsequently desensitized is also consistent with our hypothesis, because, unlike the endogenous activator cGMP, 8-Br-cGMP is resistant to hydrolysis (Zimmerman et al. 1985).

During the normal response to light, cGMP levels could be modulated either by controlling the activity of GC or PDE, or both. The effects of the GC activator SNP and the PDE inhibitor zaprinast (Fig. 3) would indicate that there is no cGMP synthesis in dark-adapted cells and that light increases CGMP levels primarily by stimulating GC activity. Following the stimulation of cyclase activity by light, it seems reasonable to believe that cGMP levels will rise until a point is reached when desensitization sets in. Desensitization may be mediated by activation of PDE [because zaprinast was found to be effective in light-adapted cultures (Fig. 3b)], but may also be a result of reduced photosensory capacity, because PhyA levels are known to be drastically reduced following exposure of dark-grown/adapted cells to light (Quail 1991). Although we have not studied which phytochrome is responsible for mediating the observed gene inductions in response to light, PhyA is probably the most likely candidate.

Concerning cGMP, direct evidence for its role in mediating phytochrome responses can only come from the demonstration that cGMP levels rise initially and then fall in response to light and that SNP and zaprinast can augment cGMP levels. We have made exhaustive attempts to measure changes in cGMP in SB-P cells using a conventional radioimmunoassay but have so far been unable to detect any convincing changes. The problem is that in the absence of real-time imaging techniques (such as are available for calcium and cAMP), it is impossible to follow changes in cGMP concentration that are relevant to signal transduction (i.e., presumably rapid and cytoplasmic and/or nuclear). Notwithstanding, an increase in chloroplastic cGMP in response to light has been reported (Brown et al. 1989). The significance of such an increase for regulating nuclear gene expression is, however, not clear at this time.

\section{Negative regulation of phytochrome signal transduction pathways}

The expression pattern of chs indicates how changes in cGMP levels may be used for both positive /for induction) and negative regulation (for desensitization) of the same target gene. In addition to these "intra-pathway" control mechanisms, we would also expect the existence of "inter-pathway" or cross-talk regulation, to allow full 
coordination of phytochrome responses. To identify such mechanisms, we have performed experiments in which signal flow through the different pathways has been manipulated. This has been done (1) by identifying pharmacological agents that are able to block specifically either the calcium- or the cGMP-dependent pathways, and ( 2 ) by manipulating directly the amounts of the signaling molecules themselves by microinjection.

Genistein specifically blocks the cGMP pathway downstream of cGMP (Fig. 4; Table 1), while trifluoperazine, nifedipine and staurosporine can block all calcium-dependent responses (i.e., the calcium pathway and the calcium/cGMP pathway) (Figs. 5 and 6; Table 1). The location of the inhibitor-sensitive components within the phytochrome signaling pathways can be mapped and their positions, based on current information, are shown in Figure 8a. Although tempting to speculate on the targets of these compounds [it is interesting, for example, that the nifedipine- and trifluoperazine-sensitive steps map exactly to where we would predict for a calcium channel and for $\mathrm{Ca}^{2+} / \mathrm{CaM}$, respectively; (Fig. $8 \mathrm{a} \mid \mathrm{l}$, it is currently too early to know anything about them. Nonetheless, this should in no way undermine their value nor should it complicate our interpretation, because, if nothing else, their specificity is absolutely clear at the level of their effects on the different phytochrome signal transduction pathways, and, furthermore, their effects in both SB-P cells and in aurea are entirely consistent. As such, it is now possible to examine the consequences of specific knockouts of individual pathways. For example, a calcium pathway knockout has the effect of superstimulating chs expression, presumably by increasing signal transduction through the cGMP pathway (Figs. 6d and 7). We believe that the inhibition of the calcium pathway is related to the superstimulation of the cGMP pathway (1) because trifluoperazine can augment both the normal light induction of chs and the 8-Br-cGMP-mediated induction, and $(2)$ because it can affect an 8-Br-cGMP-induction only in a light-adapted but not in a dark-adapted culture, that is, only when there is a calcium current. Direct evidence for this has been obtained from microinjection experiments in aurea, in which we showed that high levels of $\mathrm{Ca}^{2+}$ / CaM can inhibit the cGMP-mediated induction of chsgus (Table 2). However, while cGMP levels appear to be the primary factor for controlling chs gene expression (induction and desensitization), the negative regulation of the cGMP pathway by the calcium pathway would appear to affect primarily the induction process, because trifluoperazine and the other calcium pathway inhibitors do not appear to affect chs desensitization (Fig. 6d).

Interestingly, negative regulation also operates in the opposite direction: In all cases when chs gene expression was stimulated artificially (e.g., by 8 -Br-cGMP, SNP or zaprinast), we observed accompanying decreases in $c a b$ mRNA levels (e.g., Fig. 3 b). cab and chs mRNA abundance are very often mirror images of one another (e.g., Fig. 4b). We have also confirmed these effects in microinjection experiments, by showing that the induction of $c a b-g u s$ observed following injection of cGMP and
$\mathrm{Ca}^{2+} / \mathrm{CaM}$ can be inhibited if higher amounts of cGMP are used, whereas chs-gus is expressed as normal (Table 2).

Which signaling intermediates could mediate these negative regulatory phenomena? It is difficult to envisage calcium and CGMP in these roles because the downregulation of $c a b$ mRNA by cGMP is sensitive to genistein (Fig. 4) and because the superstimulation of chs can be mediated by trifluoperazine, nifedipine, and staurosporine (Fig. 6). This is confirmed further by the fact that injection of high amounts of $\mathrm{Ca}^{2+} / \mathrm{CaM}$ can inhibit the cGMP-mediated induction of chs-gus in aurea (Table 2). Consequently, we would predict that either $\mathrm{Ca}^{2+}$ / $\mathrm{CaM}$, something downstream of it, or both, would mediate the cross talk in one direction and that the genistein-sensitive component, something downstream of it, or both, would act in the opposite direction. These interactions are summarized in Figure $8(\mathrm{~b}, \mathrm{c})$. Because negative regulation is only manifested in the presence of high amounts of signaling intermediates, to us the most reasonable mechanistic model of negative regulation is that it is mediated by components that have only low binding affinities for the effector molecules. In this way, negative regulation will only begin to operate when signal transduction through one pathway reaches an excessive level. Its mode of action may be either by inactivation of a positive regulator or by activation of a negative element.

Another interesting observation from these microinjection experiments is that like the calcium pathway, the calcium/cGMP pathway controlling fnr-gus expression does not appear to be subject to negative regulation in the presence of high amounts of $\mathrm{Ca}^{2+} / \mathrm{CaM}$, although cGMP is able to act negatively on it when present in higher amounts (Table 2). Again, the genistein-sensitive component (or something downstream of it, or both) is responsible for this (see Results). Most probably, therefore, the target $(\mathrm{s})$ for negative regulation lies between $\mathrm{Ca}^{2+} / \mathrm{CaM}$ and the bifurcation between the calciumand calcium/cGMP-dependent pathways (Fig. 8c).

\section{Reciprocal control and its physiological significance}

Concerning the calcium- and the cGMP-dependent pathways, an increase in the activity of one appears to have a negative effect on the activity of the other in both cases. Because of this, we have termed this kind of regulation reciprocal control, which we define as the negative control of one pathway by a positively acting factor from another pathway, and vice versa. For phytochrome, its physiological relevance is likely to be at its strongest when the activity of one pathway is much greater than the activity of the other. In SB-P cells, this situation appears to occur after 3-hr (high cGMP/low $\mathrm{Ca}^{2+}$ ) and 7-hr (high $\mathrm{Ca}^{2+} /$ low cGMP) light irradiation. The following scenario of events would be consistent with all of our observations. At the early time point, negative regulation may function to stimulate the production of photoprotectants and to concomitantly suppress the buildup of photosynthetic components, ensuring that photosyn- 
a

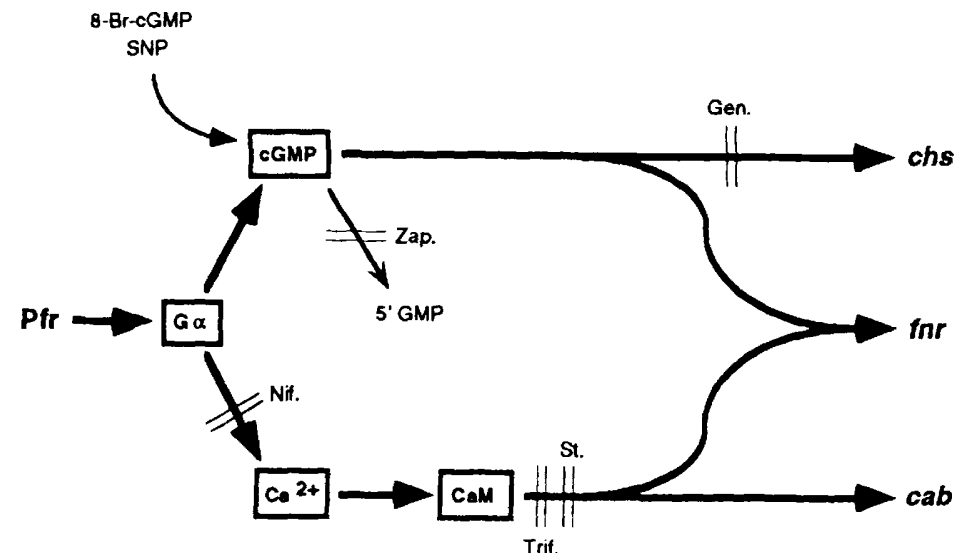

b

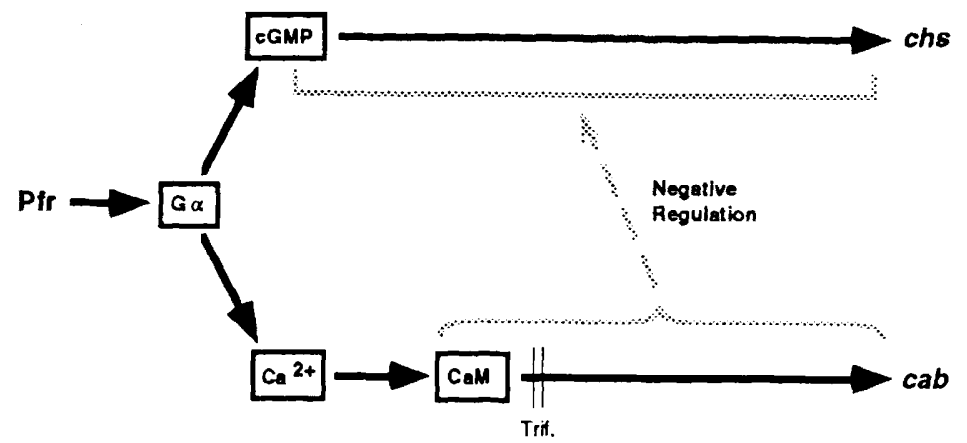

C

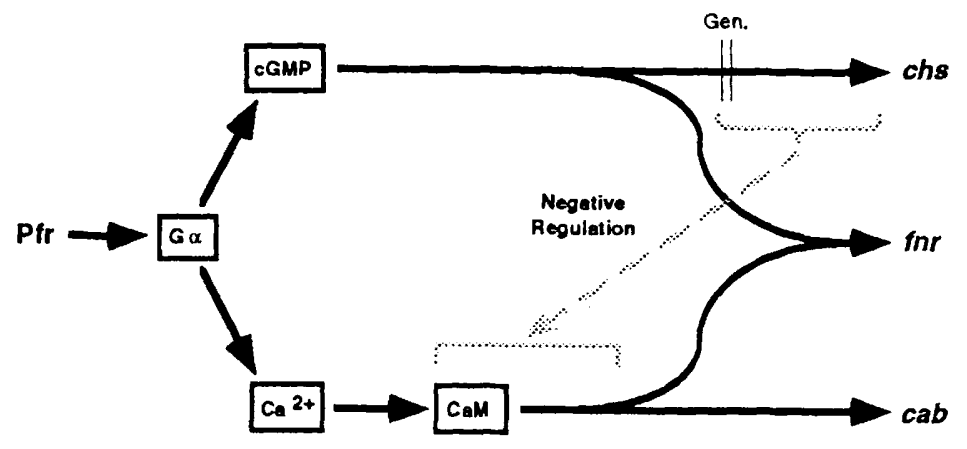

Figure 8. Summary of phytochrome signal transduction pathways. (a) Positions of the inhibitorsensitive components. The block points are indicated by two parallel lines drawn across each arrow in the pathway. $(b)$ Negative regulation of the cGMP pathway by the calcium pathway. $(c)$ Negative regulation of the calcium and calcium/ cGMP pathways by the cGMP pathway. In $b$ and $c$, the broken lines indicate the negative interactions, and brackets indicate the positions of the components that are responsible, based on current information. Abbreviations are as used in previous figures. thesis does not begin in the absence of sufficient photoprotective pigments. This would explain why negative regulation by the cGMP pathway acts on both the calcium- and the calcium/cGMP-dependent pathways, both of which are needed for the synthesis of photosynthetic components. After $3 \mathrm{hr}$, cGMP levels presumably begin to fall (switching off chs expression), by some intra-pathway mechanism, and $\mathrm{Ca}^{2+}$ begins to rise, a phenomenon that we would expect to further attenuate chs expression. The rise in $\mathrm{Ca}^{2+}$ does not, however, act neg- atively on the calcium/cGMP-dependent pathway, ensuring that all photosynthetic components can be synthesized unhindered. It is well known that anthocyanin accumulation precedes chloroplast development in germinating seedlings of several species, and this is also reflected in the levels of mRNAs encoding different components. This is a phytochrome-mediated response (Brödenfeldt and Mohr 1988; Wenng et al. 1990; Ehmann et al. 1991).

At first sight, the requirement of the calcium/cGMP. 
dependent pathway for cGMP raises problems in this model, because we would expect cGMP levels to be low at the time when $\mathrm{Ca}^{2+}$ levels are high. This problem could be overcome if its threshold for activation by cGMP is lower than it is for the cGMP pathway itself. Remarkably, this was found to be the case; coinjection of cGMP levels insufficient for chs-gus expression and anthocyanin biosynthesis, together with $\mathrm{Ca}^{2+} / \mathrm{CaM}$, resulted in fnr-gus expression (Table 2) and in the development of chloroplasts containing all of the photosynthetic complexes (data not shown).

The requirement of anthocyanin biosynthesis for high levels of cGMP would ensure their synthesis more during high irradiance conditions and would allow efficient desensitization of the genes encoding the biosynthetic enzymes as soon as they are no longer needed and when cGMP levels begin to fall. This is supported by our observations that in SB-P cells, several other genes encoding anthocyanin biosynthetic components require constant irradiation for expression, and of all the light-regulated genes studied (Bowler et al. 1994) they are the only ones that are desensitized (H. Yamagata, C. Bowler, and N.-H. Chua, unpubl.). A lower threshold requirement of the PSI and Cyt.b ${ }_{6} f$ components for cGMP would presumably permit their synthesis even when the cells are light adapted, ensuring that the genes encoding these components could be activated during conditions when the genes for anthocyanin biosynthetic enzymes are not.

In summary, the data presented here have revealed several interesting feedback mechanisms for controlling phytochrome signal transduction pathways. The relative activities of the CGMP- and the calcium-dependent pathways during different light conditions and at different times are probably key factors that determine the activities of these mechanisms. Overall, the relative push and pull between the two pathways could potentially control factors as diverse as anthocyanin-mediated photoprotection, changes in photosystem stoichiometry, and circadian rhythms, together with other light-regulated processes. Continued study of these elegant regulatory phenomena will clearly reveal novel mechanisms of cross talk between signal transduction pathways and will lead to an increased understanding of how phytochrome controls such a complex array of plant responses.

\section{Materials and methods}

\section{Soybean cell culture and RNA analysis}

The soybean (Glycine max) cell culture SB-P was first described by Horn et al. (1983). For all experiments it was grown photomixotrophically in constant light $(50 \mu$ moles/meter per sec) in $\mathrm{KN} 1$ medium (Lam et al. 1989) containing 5 grams/liter of sucrose. Ten- to- 14 -day-old cultures $(500 \mathrm{ml})$ were dark-adapted for 2.5-3 days prior to experimental manipulation. Such cultures are described in the text as dark-adapted cultures. Cultures that were subsequently exposed to light $150 \mu$ moles $/$ meter per sec) for at least $10 \mathrm{hr}$ are described as light-adapted cultures. All manipulations with dark-adapted cells were performed under green safelight conditions. Samples were col- lected on filters by suction filtration and immediately frozen in liquid nitrogen.

Although we are primarily interested in phytochrome responses, the experiments presented here have been done with white light rather than with red light. This is because we have found white light to be equivalent to red light for all the responses shown. Interestingly, signal transduction initiated by blue/UV photoreceptors is clearly different to what we have described here (manuscript in preparation).

RNA was prepared from frozen cells essentially as described by Lam et al. (1989). RNA gels (10-30 $\mu \mathrm{g} /$ lane) were blotted onto nylon filters (Stratagene) and hybridized with randomprimed probes prepared according to the manufacturers recommendations (Amersham). Soybean cDNAs encoding cab (Walling et al. 1986), chs (Estabrook and Sengupta-Gopalan 1991), and fnr (Bowler et al. 1994) were used as probes. Filters were routinely stripped and rehybridized to different probes to control loading and blotting.

\section{Treatment with chemical agonists and antagonists}

To facilitate uptake of the different compounds into the cells, we have found that acid loading greatly improves reproducibility of the reported effects. This is especially true for 8-Br-cGMP, as we reported previously (Bowler et al. 1994). Acid loading was performed by adding sufficient $50 \mu \mathrm{M} \mathrm{HCl}$ to lower the $\mathrm{pH}$ of the culture to between $\mathrm{pH} 4.0$ and $\mathrm{pH} 4.5$. The starting $\mathrm{pH}$ of a dark-adapted culture was typically about $\mathrm{pH} 6.0$, whereas that of a light-adapted culture was about pH 5.5. Conveniently, we found that the cells could buffer themselves back to their starting $\mathrm{pH}$ after $30 \mathrm{~min}-1 \mathrm{hr}$.

8-Br-cGMP (Sigma) was dissolved in 10\% DMSO and added to the cells at $1 / 1000$ dilutions. In the experiments reported here we used a final concentration of $50 \mu \mathrm{M}$, which we found to give a maximal response. However, all concentrations between 20 and $100 \mu \mathrm{M} 8$-Br-cGMP could stimulate chs gene expression to some extent. Concentrations above $100 \mu \mathrm{M}$ were never tested. These concentrations are highly similar to the concentrations found to be effective in microinjection experiments (Bowler et al. 1994) and are very similar to the endogenous concentration of cGMP in amphibian photoreceptor cells, estimated to be 60 $\mu \mathrm{M}$ (Cote et al. 1984).

SNP was obtained from Sigma and was dissolved in water at a concentration of $100 \mathrm{~mm}$. Zaprinast was a gift of Monsanto Co. (St. Louis, MO) and was dissolved in DMSO at $100 \mathrm{mM}$ concentration. Both were used at final concentrations of 100 $\mu \mathrm{M}$, which we found to be most effective, as has also been reported in animal cells (Tremblay et al. 1988). Once added, the cultures were maintained in darkness for the remainder of the experiment, even if light-adapted cultures were used. This was because both compounds appear to be light sensitive.

Genistein (Calbiochem), trifluoperazine (Calbiochem), nifedipine (Research Biochemicals Inc.), and staurosporine (Calbiochem) were dissolved in DMSO and diluted to $1 / 1000$ when added to the cultures. In appropriate experiments with darkadapted cells, the compounds were added under green safelight conditions and a further $30 \mathrm{~min}$ in darkness was allowed for entry of the compound into the cells before exposing them to light.

Each of these inhibitors was tested at several concentrations; although lower levels generally had no effect, higher levels were either toxic or gave nonspecific inhibition of all the phytochrome pathways. All stock solutions were prepared fresh before each experiment, and each experiment was repeated at least five times to produce essentially the same result in all cases. 


\section{Microinjection of aurea hypocotyls}

All standard techniques used for the microinjection and analysis of aurea hypocotyls, including descriptions of the reporter genes and preparation of injection solutions, have been described previously (Neuhaus et al. 1993; Bowler et al. 1994).

For inhibitor experiments, injected seedlings were incubated in petri dishes with $2 \mathrm{ml}$ of $50 \mu \mathrm{M}$ Tris- $\mathrm{HCl}(\mathrm{pH} 7.0)$, containing the appropriate inhibitor $(100 \mu \mathrm{M}$, genistein; $200 \mu \mathrm{M}$, trifluoperazine, $125 \mu \mathrm{M}$, nifedipine, $60 \mathrm{nM}$, staurosporine), and subsequently the seedlings were vacuum infiltrated for $1 \mathrm{~min}$. The infiltrated seedlings were then incubated in light for $48 \mathrm{hr}$ before being examined for Gus expression, chlorophyll fluorescence, anthocyanin fluorescence, or immunostaining. Genistein, nifedipine, trifluoperazine, and staurosporine were all purchased from Calbiochem and dissolved in DMSO before dilution $(1 / 1000)$ to the appropriate concentrations.

\section{Acknowledgments}

We thank N. Parekh for excellent assistance with soybean experiments and Yan Wu and A. Galli for their invaluable help in microinjection experiments. We are indebted to the following persons for their generous gifts of material: J.M. Widholm for the SB-P culture; L.L. Walling for soybean PSII $c a b$; C. Sengupta-Gopalan for soybean chs; L. Bell (Monsanto Co.) for zaprinast; J.C. Gray for the unpublished pea fnr promoter sequence; and F.M. Ausubel for the chs-gus construct. We thank R. Mayer and S.A. Barnes for critical reading of the manuscript. C.B. was supported by a SERC (NATO) postdoctoral fellowship and later by a fellowship from the Norman and Rosita Winston Foundation. G.N. was partially supported by the Huber Kudlich Stiftung (Switzerland). This work was supported by a National Institutes of Health grant (44640) to N.-H.C.

The publication costs of this article were defrayed in part by payment of page charges. This article must therefore be hereby marked "advertisement" in accordance with 18 USC section 1734 solely to indicate this fact.

\section{References}

Akiyama, T., J. Ishida, S. Nakagawa, H. Ogawara, S.-i. Watanabe, N. Itoh, M. Shibuya, and Y. Fukami. 1987. Genistein, a specific inhibitor of tyrosine-specific protein kinases. J. Biol. Chem. 262: 5592-5595.

Beavo, J.A. and D.H. Reifsnyder. 1990. Primary sequence of cyclic nucleotide phosphodiesterase isozymes and the design of selective inhibitors. Trends Pharmacol. Sci 11: 150-155.

Bowler, C., G. Neuhaus, H. Yamagata, and N.-H. Chua. 1994. Cyclic GMP and calcium mediate phytochrome phototransduction. Cell 77: 73-81.

Brödenfeldt, R. and H. Mohr. 1988. Time courses for phytochrome-induced enzyme levels in phenylpropanoid metabolism (phenylalanine ammonia-lyase, naringeninchalcone synthase) compared with time courses for phytochrome-mediated end-product accumulation (anthocyanin, quercetin). Planta 176: 383-390.

Brown, E.G., R.P. Newton, D.E. Evans, T.J. Walton, L.M. Younis, and J.M. Vaughan. 1989. Influence of light on cyclic nucleotide metabolism in plants; effect of dibutyryl cyclic nucleotides on chloroplast components. Phytochemistry 28: 2559-2563.

Bruns, B., K. Hahlbrock, and E. Schäfer. 1986. Fluence dependence of the ultraviolet-light-induced accumulation of chalcone synthase mRNA and effects of blue and far-red light in cultured parsley cells. Planta 169: 393-398.
Cote, R.H., M.S. Biernbaum, G.D. Nicol, and M.D. Bownds. 1984. Light-induced decreases in cGMP concentration precede changes in membrane permeability in frog rod photoreceptors. J. Biol. Chem. 259: 9635-9641.

Deng, X.-W. 1994. Fresh view of light signal transduction in plants. Cell 76: 423-426.

Ehmann, B., B. Ocker, and E. Schäfer. 1991. Development- and light-dependent regulation of the expression of two different chalcone synthase transcripts in mustard cotyledons. Planta 183: 416-422.

Estabrook, E.M. and C. Sengupta-Gopalan. 1991. Differential expression of phenylalanine ammonia-lyase and chalcone synthase during soybean nodule development. Plant Cell 3: 299-308.

Felix, G., D.G. Grosskopf, M. Regenass, and T. Boller. 1991. Rapid changes of protein phosphorylation are involved in transduction of the elicitor signal in plant cells. Proc. Natl. Acad. Sci. 88: 8831-8834.

Furuya, M. 1993. Phytochromes: Their molecular species, gene families, and functions. Annu. Rev. Plant Physiol. Plant Mol. Biol. 44: 617-645.

Horn, M.E., J.H. Sherrard, and J.M. Widholm. 1983. Photoautotrophic growth of soybean cells in suspension culture. Plant Physiol. 72: 426-429.

Huang, J., M. Nasr, Y. Kim, and H.R. Matthews. 1992. Genistein inhibits protein histidine kinase. J. Biol. Chem. 267: 1551115515.

Jansson, S., E. Pichersky, R. Bassi, B.R. Green, M. Ikeuchi, A. Melis, D.J. Simpson, M. Spangfort, L.A. Staehelin, and J.P. Thornber. 1992. A nomenclature for the genes encoding the chlorophyll $a / b$-binding proteins of higher plants. Plant Mol. Biol. Reporter 10: 242-253.

Koutalos, Y. and K.-W. Yau. 1993. A rich complexity emerges in phototransduction. Curr. Opin. Neurobiol. 3: 513-519.

Kubasek, W.L., B.W. Shirley, A. McKillop, H. Goodman, W. Briggs, and F.M. Ausubel. 1992. Regulation of flavonoid biosynthetic genes in germinating Arabidopsis seedlings. Plant Cell 4: 1229-1236.

Lam, E., M. Benedyk, and N.-H. Chua. 1989. Characterization of phytochrome-regulated gene expression in a photoautotrophic cell suspension: Possible role for calmodulin. Mol. Cell. Biol. 9: 4819-4823.

Lefkowitz, R.J. 1993. G protein-coupled receptor kinases. Cell 74: 409-412.

Massom, L., H. Lee, and H.W. Jarrett. 1990. Trifluoperazine binding to porcine brain calmodulin and skeletal muscle troponin C. Biochemistry 29: 671-681.

Millar, A.J., S.R. Short, N.-H. Chua, and S.A. Kay. 1992. A novel circadian phenotype based on firefly luciferase expression in transgenic plants. Plant Cell 4: 1075-1087.

Mohr, H. and H. Drumm-Herrel. 1983. Coaction between phytochrome and blue/UV light in anthocyanin synthesis in seedlings. Physiol. Plant 58: 408-414.

Moncada, S., R.M.J. Palmer, and E.A. Higgs. 1991. Nitric oxide: Physiology, pathophysiology, and pharmacology. Pharmacol. Rev. 43: 109-142.

Neuhaus, G., C. Bowler, R. Kern, and N.-H. Chua. 1993. Calcium/calmodulin-dependent and -independent phytochrome signal transduction pathways. Cell 73: 937-952.

Ohl, S., K. Hahlbrock, and E. Schäfer. 1989. A stable blue-lightderived signal modulates ultraviolet-light-induced activation of the chalcone-synthase gene in cultured parsley cells. Planta 177: 228-236.

Quail, P.H. 1991. Phytochrome: A light-activated molecular switch that regulates plant gene expression. Annu. Rev. Genet. 25: 389-409. 


\section{Bowler et al.}

Romero, L.C. and E. Lam. 1993. Guanine nucleotide binding protein involvement in early steps of phytochrome-regulated gene expression. Proc. Natl. Acad. Sci. 90: 1465-1469.

Rüegg, U.T. and G.M. Burgess. 1989. Staurosporine, K-252 and UCN-01: Potent but nonspecific inhibitors of protein kinases. Trends Pharmacol. Sci. 10: 218-220.

Schroeder, J.I. and P. Thuleau. 1991. $\mathrm{Ca}^{2+}$ channels in higher plant cells. Plant Cell 3: 555-559.

Schumaker, K.S. and M.J. Gizinski. 1993. Cytokinin stimulates dihydropyridine-sensitive calcium uptake in moss protoplasts. Proc. Natl. Acad. Sci. 90: 10937-10941.

Tremblay, J., R. Gerzer, and P. Hamet. 1988. Cyclic GMP in cell function. In Advances in second messenger and phosphoprotein research (ed. P. Greengard and G.A. Robison), Vol. 22, pp. 319-383. Raven Press, New York.

Walling, L., G.N. Drews, and R.B. Goldberg. 1986. Transcriptional and post-transcriptional regulation of soybean seed protein mRNA levels. Proc. Natl. Acad. Sci. 83: 2123-2127.

Wenng, A., A. Batschauer, B. Ehmann, and E. Schäfer. 1990. Temporal pattern of gene expression in cotyledons of mustard (Sinapis alba L.) seedlings. Bot. Acta 103: 240-243.

Zimmerman, A.L., G. Yamanaka, F. Eckstein, D.A. Baylor, and L. Stryer. 1985. Interaction of hydrolysis-resistant analogs of cyclic GMP with the phosphodiesterase and light-sensitive channel of retinal rod outer segments. Proc. Natl. Acad. Sci. 82: 8813-8817. 


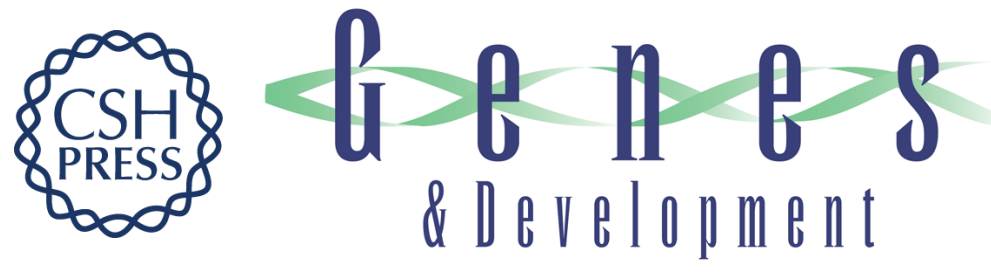

\section{Phytochrome signal transduction pathways are regulated by reciprocal control mechanisms.}

C Bowler, H Yamagata, G Neuhaus, et al.

Genes Dev. 1994, 8:

Access the most recent version at doi:10.1101/gad.8.18.2188

References This article cites 33 articles, 13 of which can be accessed free at:

http://genesdev.cshlp.org/content/8/18/2188.full.html\#ref-list-1

License

Email Alerting

Service

Receive free email alerts when new articles cite this article - sign up in the box at the top right corner of the article or click here.

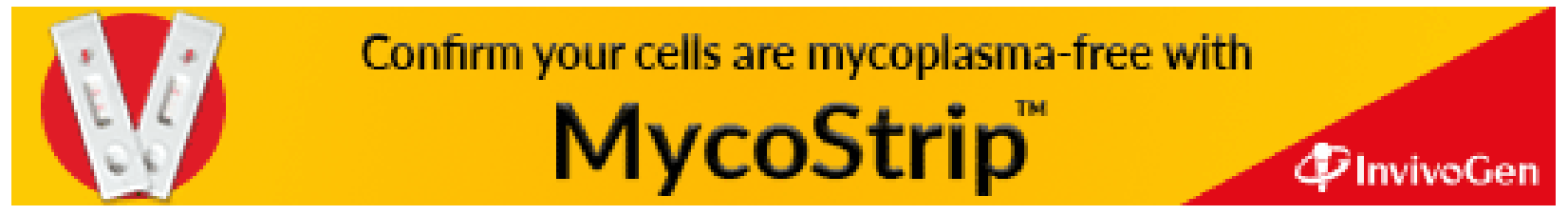

